\title{
The Successive Impact of the Green Organizational Strategies and Green Innovation in Enhancing the Sustainable Competitive Advantage
}

\author{
Baser Khalf Khazeal ${ }^{1}$ and Majeed Hameed Majeed ${ }^{2}$ \\ \{ baserbbbb@gmail.com ${ }^{1}$, mageed_h2003@yahoo.com ${ }^{2}$ \} \\ ${ }^{1}$ Baser Khalf Khazeal, Department of Management Office, Northern Technical University. \\ ${ }^{2}$ Northern Technical University
}

\begin{abstract}
The current study aims at determining the successive impact of the organizational green strategies in green innovation and their impact on enhancing the sustainable competitive advantage in Karwanchi Group Kirkuk. This study has depended on both the descriptive and analytical approaches and the data were collected based on a sample of 94 workers and depending on a questionnaire prepared for this study. The statistical analysis of the data collected was conducted using SPSS. V. 24. This study ended with several important conclusions: the green organizing strategies have a direct important impact on the sustainable competitive advantage less than the rate of the indirect impact with green innovation. The new value has thus been added to enhance the sustainable competitive advantages in the studied group (company). This study ended also with several recommendations. The most important recommendation is that the higher management in the company should build green organizational strategies that support innovation.
\end{abstract}

Keywords: Green organizing strategies, green innovation, sustainable competitive advantages.

\section{Introduction}

The environment is considered a focal item which should be considered in all managerial practices and styles whereby the company can make a balance between work and the pressures and the national, regional, and international environmental legislations. Thus, companies nowadays should implement environment protection activities to abide by international environment protection legislations and enhance environmental awareness for customers and clients. The adoption of environmental management activities does not only include coping with pressures and environmental awareness of customers but also helping companies to create new opportunities in the market and enhancing the sustainable competitive advantages. Thus, green innovation has become an important concept that considers the response to the clients' desires and the pressures of international legislations. The green innovation does not emerge out of a vacuum but is also impacted by internal and external organizational factors. These factors are considered strategies that the company can use to enhance the green innovation. Thus, companies play an important role in accelerating and enhancing the rhythm of green innovation through supporting green organizational strategies whether being internal or external because nowadays' competition has become the most important element in the new work system that depends on green innovation. This research examined the relationship of sequential effects 
between study variables, which differed from previous studies [ADD References] in their variables. To do so, this study has fallen into four sections: the first one deals with the theoretical framework, the second one is dedicated to the study methodology, the third one represents the practical side, and the fourth section is dedicated to the recommendations and conclusions.

\section{The Theoretical Framework}

\subsection{The concept of green organizational strategies}

Due to the ongoing increasing industrial activities, and since the industrial revolution, there has been an emerging global problem in the world today, in order to protect the world, it is necessary to depend on a protective approach to terminate the problem of environmental pollution. Currently, there is a consideration of following up the environment management concepts such as green management, green shopping, green production, and green innovation. Scientists have recently started focusing on the role that organizational infrastructures play [1]. Green organizational strategies is a concept used to describe the organizational strategies to a certain external force that impacts the level of green innovation [2]. This concept is also used to describe the internal dynamic advantages and features within the organizational framework [3]. The most important factor to achieve the goals of green innovation is to develop green capacities of the company which can be enhanced through green organizational strategies (supporting higher management, training, investing in research and development, cooperation networking, and the environmental management systems) that have a positive impact on the green innovation performance [4]. Having said so, green innovation aims at matching and implementing these strategies in an organized way to develop new products and services [5]. Thus, we suggest that each of these four types of green organizational strategies (training, investing in research and development, cooperation networking, and environment management systems) has a positive impact on green innovation. Having said so, this study will depend on [4]. model in determining the green organizational strategies. They are the following:

1- The higher management: As higher management is supportive of green innovation activities, it could also help the organization to build a good reputation and relationships with governmental agencies [6].

2- Training: Training refers to a series of environment activities that workers practice and that aim at achieving certain goals such as training workers on approaches and ecological design technologies, recycling materials, or using a cleaner or renewable technologies [7].

3- Research and development: The real success of green innovation depends to a large extent on research and development in the company. Some empirical findings have shown that companies are more likely to increase investments in environment research and development and to renewing technologies to prevent pollution according to the strict bylaws and regulations [8].

4- Cooperation networking: It seems that external knowledge is more important in regards to green innovation in comparison with other types of innovations. Thus, companies sometimes expand their external knowledge sources through enhancing their capacities of cooperation networking [9].

5- Environmental management systems: Organizational capacities play an important role in innovation where environmental organizational capacities are built through 
implementing environmental management systems which are considered a central factor in implementing green innovation [10].

\subsection{The concept of green innovation}

Companies work on developing several environment-friendly programs and green products as well as green management operations. It has become very important for companies to increase their environmental awareness because more international clients and purchasers ask their providers to produce products that do not contain dangerous or poisonous materials. They also expect their providers to decrease their consumption of natural energy in the process of production to decrease the negative consequences on the environment and also expect companies to have a reach to sustainable development.

Environmental issues can impact the strategies of companies and the policies of governments. Thus, green innovation is considered the solution to meet the environment requirements and sustainable growth for companies [11]. There has been an increase in the number of companies that adopt green innovation strategies as a means to achieve more sustainable competitive advantages. Thus, many companies have developed several environment-friendly programs such as green products, and green technologies that can be used to improve their green innovation [12]. Companies have found that participating in green innovation is a way to progress toward responding to the increasing environmental challenge [13].

In recent years, green innovation has become one of the strategic and important tools that are used to achieve sustainable competitive advantages in the industrial sector in response to the increasing environmental pressure [14]. Green innovation is in fact not a one-way process with inputs producing outputs but a complicated process covering internal systems, workers, and external environments. All these elements have an impact on green innovation. Thus, building an appropriate framework is necessary to measure the dynamic nature of green innovation (Park, 2017, p.3). Many researchers have agreed and disagreed on giving a specific concept to green innovation. [15], [16], [17], [18] have agreed on defining green innovation as innovating equipment and programs that relate to products and green operations including innovating technologies that save energy and prevent pollution, recycling wastage and garbage, designing green products and managing the environment in efficient ways. [12] states that it refers to the development of new ideas about green products or green services or even operations or practices that are considered innovative and useful. Throughout the discussion above, there are two important points about green innovation to consider: 1) It is the development of new ideas, behaviors, products, and operations and applying or rendering them. 2) Contributing to the decrease of environmental burdens and harms and achieving specific sustainable goals about the environment.

\subsection{Types of Green Innovation}

In recent years, more attention has been paid to innovation and especially green innovation by companies and it has become a priority for these companies. Researchers have started to focus more on the forcing powers and factors for green innovation [19]. Some researchers have found that internal organizational factors affect green innovation [12]. For example[20] classified it into four types including innovation in products, operations, managerial innovation, and marketing innovation. At the same time, green innovation can be classified into three main types: innovation in green products, innovation in green operations, and green management 
innovation [21]. In the meanwhile, [18],[22] classified green innovations into two types: green products innovations (providing new green products for customers and clients) and innovations in green operations (providing work operations). it has been said that the driving forces for the green innovation practices were unbalanced or non-harmonious. Thus, more studies about green innovation need to be conducted in a more comprehensive framework. Having said so, this study focused on two dimensions that most researchers agreed upon to measure green innovation (Tang, 1998; Henriques and Sadorsky, 2007, 2011; Frondel, et al, 2008) [23]. They are; 1) Innovation in green products: green product innovation is determined by introducing new improved products to a large extent, This included improvements on the used products in terms of the basic or technical characteristics or programs [22]. 2) Innovation in green operations: it refers to the change in the production operations and the systems of managing environmentfriendly products that meet the environmental goals (for example, saving energy and preventing pollution as well as recycling) [5], [14].

\subsection{Sustainable competitive advantage}

Within the current international green management, the competition in the international industries has become more complex and uncertain. Most developments in technologies and products are moving toward green framework. This movement has been associated with the accountability and responsibility of the bad effects on environment in reaction to work strategies all led to huge changes in the social system and the competition arena [24]. The concept of sustainable competitive advantage was introduced in 1984 where was on the strategies that keep the competitive advantage. The concept of sustainable competitive advantage has been developed deeply in 1985 by Porter through a diverse set of competitive strategies (leading cost, distinction, and focus) to achieve a distinct competitive advantage in the long term. Despite all that, Porter did not provide a definition of sustainable competitive advantage. In 1991, Barney introduced the closest definition of sustainable competitive advantage such as the continuity in benefits and applying strategies that create unique value where other competitors cannot imitate as it becomes unique and exclusive to the company [25]. Dickson (1992) and Hamel and Prahalad (1989) discussed how companies need to create new merits that keep them in the front and advance in comparison with other competing companies and also to search for ways for distinction [26].

Focusing on some competitive priorities, abilities, and practices in the fields of main decisions and the internal balance can be the basis to achieve a sustainable advantage [10]. When companies are willing to enhance their competitive advantages through green innovation, they should assure their green innovation in advance [16].

\section{The methodology}

\subsection{The problem of the study}

The development that the world has witnessed and the high competition, as well as the increasing interest in the different environmental orientations, imposed a need for studying the target company in this study to explore how it works toward creating a sustainable competitive advantage because the competitive practices and the environmental orientations change as well as the change the tastes and needs of the clients toward those products that are harmful to the 
environment. This increasing awareness created a sense in society toward the environmental problems and the need to search for green strategy tools whereby environmentally unharmful products are produced. The adoption of green innovation can be one of the strategy tools to achieve sustainable competitive advantage. Based on the previous discussion, this study focused on tests and exploring the direct linear relationship between organizational green strategies and green innovation and their reflection on the sustainable competitive advantage in the studied company. Thus, the problem of the study can be summarized in the following:

1- What is the level of the organizational green strategies in the studied company?

2- What is the level of the green innovation in the studied company?

3- Does the studied company have a sustainable competitive advantage?

4- What is the relationship between the green organizational strategies and green innovation?

5- What is the relationship between green innovation and sustainable competitive advantage?

6- Do green organizational strategies enhance the sustainable competitive advantage in the presence of green innovation in the studied company?

\subsection{The significance of the study}

The findings of this study can provide a vision toward how to establish strategic management of green innovation in the studied company and directing its attention to the role that green organizational strategies play in enhancing green innovation and sustainable competitive advantage. In addition to this, it also aims at showing the impact relationship between green organizational strategies in green innovation and the competitive advantage in the studied company.

\subsection{Objectives of the study}

This study aims at the following

1- Introducing a theoretical framework for the managers and the workers in the studied company about the concept of green organizational strategies, green innovation, and competitive advantage

2- Test the significant relationship (correlation and successive impact) among the study 3variables in the studied company.

\subsection{The study hypothetical framework}

The study hypothetical framework was designed as in figure (1) to refer to the successful relationship between the green organizational strategies, green innovation, and competitive advantage. 


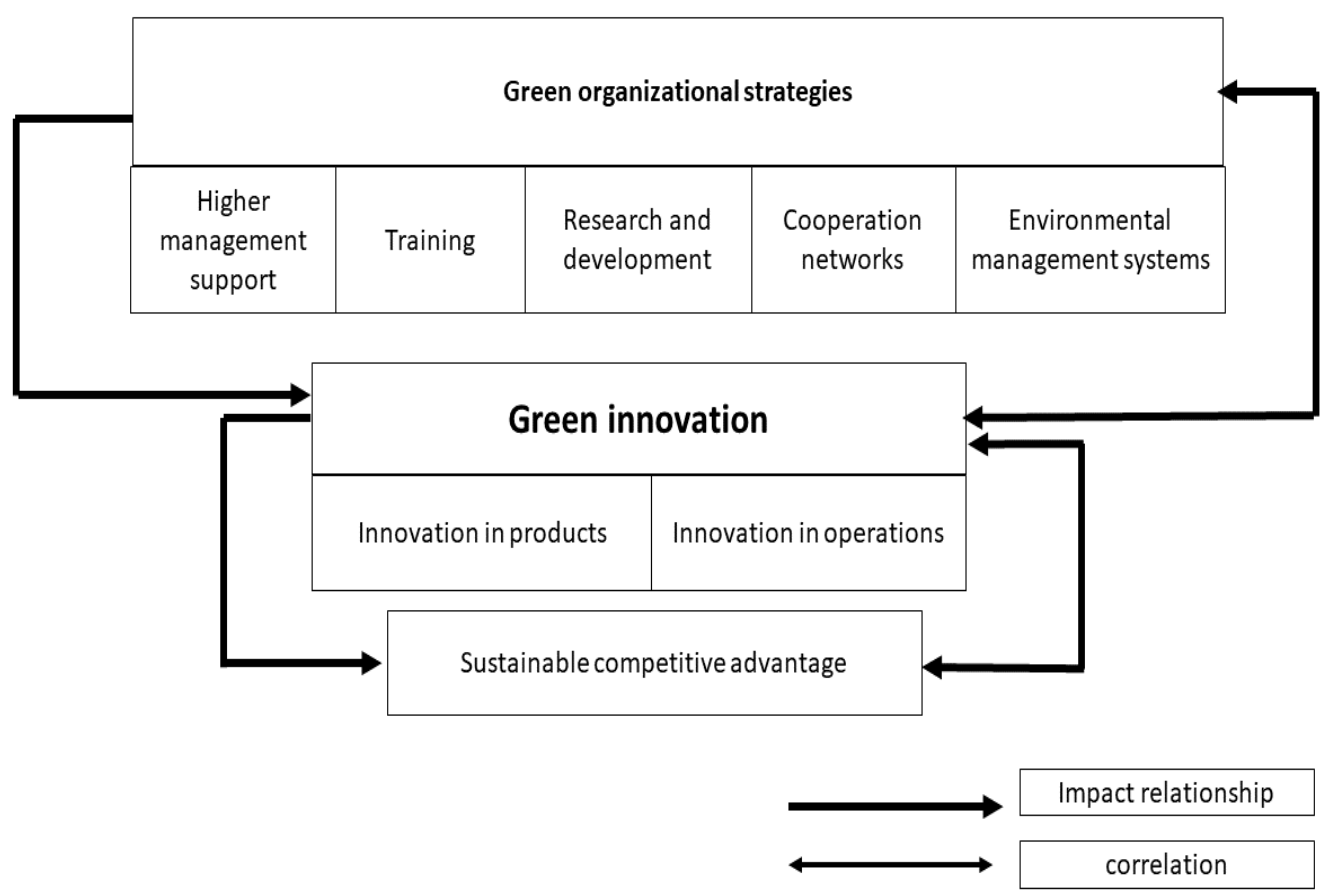

Fig. 1. The study hypothetical sample

\subsection{The study hypotheses:}

3.5.1 The first hypothesis: There is a significant correlation between the green organizational strategies and green innovation in the studied company.

3.5.2 The second hypothesis: There is a significant correlation between green innovation and the competitive advantage.

3.5.3 The third hypothesis: The impact of the green organizational strategies on the sustainable competitive advantage in the studied company varies in the presence of green innovation.

3.6 The methodology: In this study, the researchers depended on the descriptive and analytical approaches in describing the study sample, as well as in analyzing the relationship between the dependent and independent variables used.

\subsection{The study population and sample}

The Karwanchi Group in Kirkuk was selected as the study sample due to spatial closeness where the study population included 400 workers and employees. The study population represented a first sample of 100 workers on the production line. A questionnaire was distributed to them to complete. The number then decreased to 94 questionnaires valid for analysis while 6 questionnaires were not returned to the researchers. 


\subsection{Data collection}

The researchers depended on literature from different resources as well as on the distributed questionnaires to collect data about the fieldwork. The questionnaire was prepared considering the achieved scientific vision through using the scientific resources and considering the green organizational strategies variables where the related statements and phrases included in the questionnaire depended on [4]. The statements related to green innovation were prepared depending on several studies and perspectives including [14], [21], [22].

\section{The practical side}

To answer the study questions and test their hypotheses, correlations need to be found and shown. Thus, this section aims at shedding light on the study population in addition to testing the hypotheses and interpreting its findings by using a set of statistical tests. This section is divided into:

\subsection{Describing the study site: An introduction to Karwanchi Group}

Karwanchi Group is one of the most important companies that provide the local markets in Iraq with its products that entered most houses. The reason for this widespread use of its products is its high quality that made them very marketable. It has started with the Karwanchi family with Al Tamim company for soft drinks in Kirkuk city since 1999 with two production lines. In 2007, another company was launched with the name "Mina" for healthy waters with six production lines. In 2010, Al Karwanchi company for soft drinks and healthy water, juices, and dairy products were launched. It is considered one of the biggest companies in Iraq in terms of buildings and the types of products as well as in the size of the company (40 acres) and production lines and production. It is also the first and biggest company in Iraq for producing light drinks as it competed with other foreign companies whose products entered into the Iraqi market. Its success was due to the good quality of its products and its diversity. The current study only focused on Karwanchi Group (Al Tamim, Mina, and Karawnejee) for soft drinks, juices, and mineral waters with the following products: Tazaj, Karawenjee, Tam, Timsah, Fireball, Karwan water, Mina water, Tamim water, Yaoomy water) because the principles of companies are situated in healthy standards and increasing the quality of products and working toward producing healthy and safe products for their clients, and also providing new juices and waters with international standards and with different tastes and sizes that meet the tastes of those clients. The goal of the company is to move forward toward more innovation and setting ahead a vision of expansion and lead in mass and retail sales. It also should work to provide the highest quality of products in addition to the effect of their products and operations on the local environment in Kirkuk which could affect the consumption, energy, emission, and energy which might be harmful to the environment. Their goals should be working toward more innovation in products and operations.

\subsection{Description and a diagnosis of the variables of the study}

In this sub-section, the researchers describe the study variables. Thus, it is divided into the following:

\subsubsection{A description and a diagnosis of the green organizational strategies:}


The first question is "what is the level of green organizational strategies in the studied companies". The findings in Table 1 show the agreement and the means and standard deviation for the green organizational strategies in the studied company. The findings refer to a high rate of a good agreement which affects the rate of total agreement for the strategies and means which is the highest in the hypothetical mean (2). We can note that the highest mean for the three total indicators was for the support of the higher green management with an expenditure of $75 \%$ and a mean (2.665) and a standard deviation (0.620) in comparison with the other dimensions. This finding refers to high support by the management in the studied company to an environmental orientation which resulted in an important strategic resource in supporting green innovations through effective communication and starting with programs that support green innovation initiatives, and their compliance with environmental issues that save sufficient resources to support such initiatives. This study is consistent with [4] were both studies agreed that research and development and cooperation networks are important organizational strategies in the company because it obtained the highest agreement with two different variables.

Table 1. the questionnaire opinions about the green organizational strategies in the studied company Reference: This table is designed by the researchers

\begin{tabular}{ccccc}
\hline Serial & Dimensions & $\begin{array}{c}\text { Agreement } \\
\text { rate }\end{array}$ & Mean & $\begin{array}{c}\text { Standard } \\
\text { deviation }\end{array}$ \\
\hline X1 & Support for green higher management & 75 & 0.620 & 0.620 \\
X2 & Green training & 58 & 0.692 & 0.692 \\
X3 & Green research and development & 57 & 0.745 & 0.745 \\
X4 & Green cooperation networks & 66 & 0.775 & 0.775 \\
X5 & Green environmental management & 63 & 0.695 & 0.695 \\
\hline
\end{tabular}

4.2.2 The opinions collected from the questionnaires about the green innovation in the studied companies

To answer the question: "what is the level of green innovation in the studied company?", several findings were reached as in Table 2 with percentages, means, and standard deviation of green innovation in the studied company. These findings refer to an appropriate rate of the agreement which highlights the total agreement rates. We can note that the highest mean was for innovation in products with an agreement rate of (42\%) and a mean (2.241) and a standard deviation (0.696) in comparison with innovation in green operations which was also higher than the hypothetical mean (2). Also, the current study is consistent with [22] study that companies must realize that the positive impact of green products and processes can increase the performance of companies despite different variables of these studies.

Table 2. the questionnaire opinions about green innovation in the studied company

Reference. The table was designed by the researchers using the output from SPSS. V.24. N=94

\begin{tabular}{ccccc}
\hline Serial & Dimensions & Agreement rate & Mean & Standard deviation \\
\hline X6 & Green products & $42 \%$ & 2.241 & 0.696 \\
X7 & Green operations & $41 \%$ & 2.160 & 0.653 \\
\hline
\end{tabular}

4.2.3 The opinions of the study sample participants about the sustainable competitive advantage in the studied company 
To answer the third question: "does the studied company have a sustainable competitive advantage?", the findings in Table 3 indicate the percentages, means, and standard deviation to the sustainable competitive advantage. It shows a good agreement rate where the agreement rate is $51 \%$, the mean is (2.418), and the standard deviation is (0.645) which is higher than the hypothetical mean (2). The previous findings point out that the studied company has a sustainable competitive advantage through achieving a better performance in comparison with competitors in decreasing the use of energy, costs, wastage, and emissions in its production.

Table 3. the questionnaire opinions about the sustainable competitive advantage

Reference. The table was designed by the researchers using the output from SPSS. V.24. N=94

\begin{tabular}{ccccc}
\hline Serial & Dimensions & Agreement rate & Mean & Standard deviation \\
\hline $\mathrm{X} 8$ & Sustainable competitive advantage & $51 \%$ & 2.418 & 0.645 \\
\hline
\end{tabular}

\subsection{The analysis of the correlation between the green organizational strategies and green innovation}

To answer the fourth question: "what is the relationship between the green organizational strategies and green innovation in the studied company?" which was set up in a hypothesis form: "there is a significant correlation between the green organizational strategies and green innovation in the studied company." The findings in Table 4 show a positive significant correlation between the green organizational strategies and green innovation on the total scale where the correlation (the total indicator) $\left(0.735^{* *}\right)$ with a P-value $(0.05)$.

Table 4. The findings of the correlation between the green organizational strategies and green innovation.

\begin{tabular}{cc}
\hline The dependent variable & \\
The independent variable & The green organizational strategies \\
\hline Support from higher management & $0.764^{* *}$ \\
Green training & $0.753^{* *}$ \\
Green research and development & $0.717^{* *}$ \\
Green cooperation networks & $0.602^{* *}$ \\
Green environmental management systems & $0.674^{* *}$ \\
The total indicator & $\mathbf{0 . 7 0 5}^{* *}$ \\
\hline
\end{tabular}

Reference. This table was designed by the researchers based on the outputs. $\mathrm{P}<0.05 \quad \mathrm{~N}=94$

\subsection{The correlation between green innovation and sustainable competitive advantage}

The fifth question: "what is the relationship between green innovation and sustainable competitive advantage in the studied company?", was set up in a hypothesis form. Table 5 shows the correlation between green innovation and sustainable competitive advantage in the studied company. It shows a significant correlation between green innovation and sustainable competitive advantage in the studied company. The value of the total indictor with a correlation $(* 0.746)$. 
Table 5. The correlation findings between green innovation and the sustainable competitive advantage.

The dependent variable The independent variable

$\begin{array}{cc}\text { Green innovation in products } & 0.763^{*} \\ \text { Green innovation in operations } & 0.734^{*} \\ \text { The total indicator } & 0.746^{*}\end{array}$

Reference. This table was designed by the researchers based on o the outputs of SPSS. V. 24, P $\leq 0.05$ , $\mathrm{n}=94$

\subsection{Testing the successive impact among the study variables}

The sixth question of this study: "Do green organizational strategies contribute to supporting the sustainable competitive advantage in the presence of green innovation in the studied company?". This question was set up in the third main hypothesis form. The findings of the analysis of the multiple linear regression for the study variables as in tables (6 and 7).

Table 6. The impact of the green organizational strategies and green innovation on the sustainable competitive advantage.

\begin{tabular}{|c|c|c|c|c|c|c|c|c|c|}
\hline 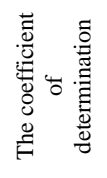 & 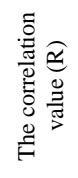 & $\underset{\underline{s}}{\vec{s}}$ & 莺 & 总 & 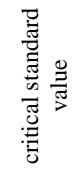 & 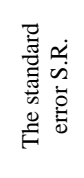 & 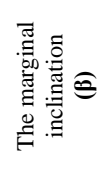 & 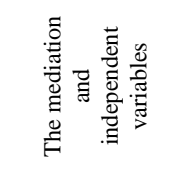 & 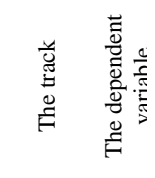 \\
\hline \multirow{2}{*}{$\begin{array}{c}0.68 \\
6\end{array}$} & \multirow{2}{*}{$\begin{array}{c}0.72 \\
8\end{array}$} & \multirow{2}{*}{$\begin{array}{c}149.93 \\
5\end{array}$} & $\begin{array}{c}\text { Statistical } \\
\text { significanc } \\
\mathrm{e}\end{array}$ & $* * *$ & $\begin{array}{c}9.99 \\
3\end{array}$ & $\begin{array}{c}0.07 \\
2\end{array}$ & $\begin{array}{c}0.72 \\
2\end{array}$ & $\begin{array}{c}\text { Green } \\
\text { innovation }\end{array}$ & \\
\hline & & & $\begin{array}{c}\text { Statistical } \\
\text { significanc } \\
\mathrm{e} \\
\end{array}$ & $\begin{array}{c}0.03 \\
9\end{array}$ & $\begin{array}{c}2.06 \\
2\end{array}$ & $\begin{array}{c}0.06 \\
8\end{array}$ & $\begin{array}{c}0.14 \\
0\end{array}$ & $\begin{array}{c}\text { Green } \\
\text { organizationa } \\
1 \text { strategies }\end{array}$ & \\
\hline
\end{tabular}

Where the analysis is conducted using the multiple linear regression as follows, see equation (1) (2):

$$
\begin{aligned}
& Y=a+\beta_{1}(X)+\beta_{2}(M) \\
& Y=0.440+0.140(X)+0.722(M)
\end{aligned}
$$

1- The standard value (C.R.) (between the green organizational strategies and the sustainable competitive value) is (2.062) which is higher than the critical standard value (1.69) with a $\mathrm{P}$-value (0.039) and is smaller than the average P-value (0.05). This finding indicates a significant impact between the green organizational strategies in the sustainable competitive advantage where it reached a value $(0.140)$ and thus indicates that when green organizational strategies with one unit, it leads to an increase in the sustainable competitive advantage of $14 \%$.

2- The standard value (C.R.) (between the green organizational strategies and green innovation) is (13.213) which is higher than the critical standard value (1.69) with a Pvalue $(0.000)$ which is smaller than the average $\mathrm{P}$-value $(0.05)$ and thus indicates that there is a significant impact for strategic planning in the organizational performance where the value of impact between them reached (0.699). This finding means that when the higher 
management is more dedicated to the green organization with one unit, that leads to supporting green innovation with (the marginal inclination number)

3- The standard value (C.R.) (between green innovation and the sustainable competitive advantage) is (9.993) which is higher than the critical standard value (1.69) with a P-value (0.000) which is smaller than the average P-value (0.05). This finding indicates a significant impact for the green innovation variables and dimensions in the sustainable competitive advantage where the value of impact reached (0.722) and this indicates that when more dedication is given to green innovation dimensions with one unit, that will lead to supporting the sustainable competitive value with $72 \%$

Table 7. The direct and indirect impact of the green organizational strategies on the sustainable competitive advantage with the existence of green innovation.

\begin{tabular}{|c|c|c|c|c|c|c|c|c|}
\hline $\begin{array}{l}\text { The type } \\
\text { of } \\
\text { mediation }\end{array}$ & \multicolumn{2}{|c|}{$\begin{array}{l}\text { The } \\
\text { significance }\end{array}$} & \multicolumn{2}{|c|}{ C.R. } & \multicolumn{2}{|c|}{$\begin{array}{c}\text { The } \\
\text { direct } \\
\text { impact }\end{array}$} & $\begin{array}{c}\text { The } \\
\text { indirect } \\
\text { impact }\end{array}$ & The study variables \\
\hline --- & $\begin{array}{l}\text { Statistical } \\
\text { significance }\end{array}$ & $* * *$ & 13.213 & 0.053 & 0.699 & --- & $\begin{array}{c}\text { Green } \\
\text { organizational } \\
\text { strategies }\end{array}$ & $\begin{array}{c}\text { Green } \\
\text { innovation }\end{array}$ \\
\hline $\begin{array}{c}\text { Total } \\
\text { mediation }\end{array}$ & $\begin{array}{l}\text { Statistical } \\
\text { significance }\end{array}$ & .039 & 2.062 & 0.068 & 0.140 & 0.505 & $\begin{array}{l}\text { Green } \\
\text { organizational } \\
\text { strategies }\end{array}$ & $\begin{array}{c}\text { The } \\
\text { sustainable } \\
\text { competitive } \\
\text { advantage }\end{array}$ \\
\hline --- & $\begin{array}{l}\text { Statistical } \\
\text { significance }\end{array}$ & $* * *$ & 9.993 & 0.072 & 0.722 & --- & $\begin{array}{l}\text { Green } \\
\text { innovation }\end{array}$ & $\begin{array}{c}\text { The } \\
\text { sustainable } \\
\text { competitive } \\
\text { advantage }\end{array}$ \\
\hline
\end{tabular}

Reference. This table was designed by the researchers based on the outputs of SPSS. V. 24

After making sure of the impact of green organizational strategies on green innovation, and the impact of green innovation in sustainable competitive advantage, we can say that green innovation is considered an intermediary variable. Thus, the fifth hypothesis will be tested. It states: "the impact of green organizational strategies on sustainable competitive advantage varies with the presence of green innovation in the studied company." The findings showed that the value of the indirect impact for the green organizational strategies on the sustainable competitive advantage that reached (0.505) which is higher than the direct impact value that reached (0.140). That is, the total positive impact for the green organizational strategies in the sustainable competitive advantage $(0.140+0.505)$ which reached $(0.645)$. This finding indicates that the green innovation variable added a new value between the independent variable (green organizational strategies) and the dependent variable (the sustainable competitive advantage). And as the value of the indirect impact is higher than the value of the direct impact, the mediation between the green organizational strategies and green performance is a total mediation. That is, the indirect impact only represents (27\%) out of the direct impact. It means that strategic planning impacts the sustainable competitive advantage directly $(21 \%)$ while its indirect impact along with green innovation represented $(78 \%)$ out of the total impact. This finding matches with the current study methodology and its goals and thus assuring on accepting the five hypotheses in this study. The direct and indirect impact of green organizational strategies in the sustainable competitive advantage can be clarified as in the following figure (figure 2): 


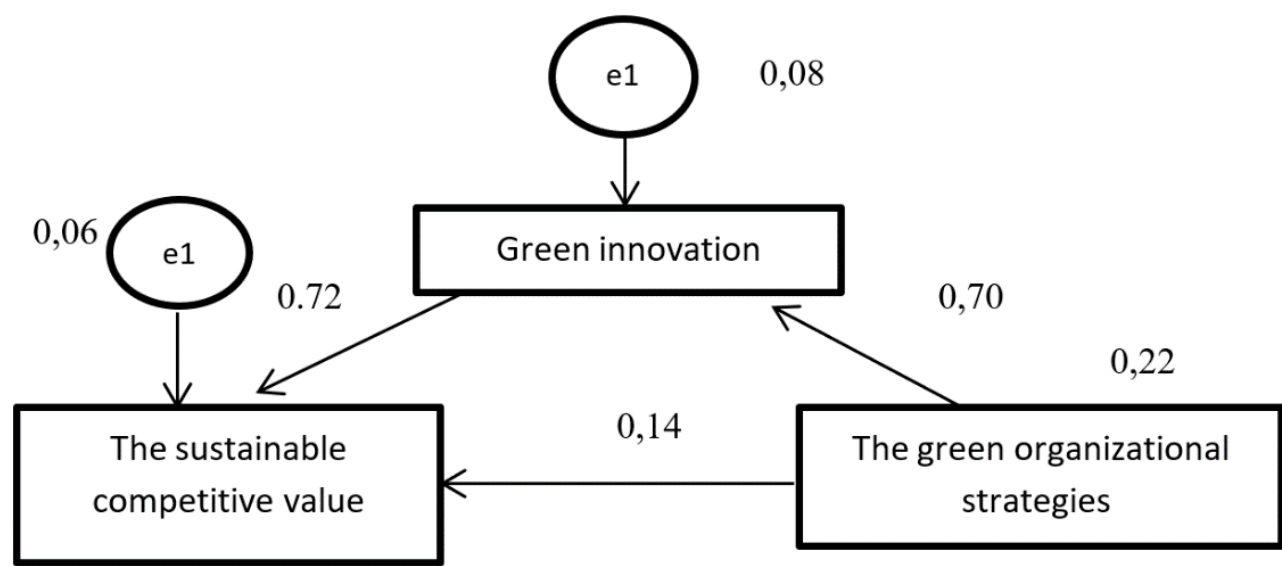

Fig. 2. The impact of green organizational strategies on sustainable competitive advantage with the existence of green innovation.

To assure that the mean (green innovation) between (the green organizational strategies and the sustainable competitive advantage) will be tested using Soble test and as shown in tables (8 and 9) where they show the values of the test as greater than the critical standard value (1.96) and this assures that the mediation variable which is represented by green innovation has an impact between green organizational strategies on the sustainable competitive advantage.

\begin{tabular}{|c|c|c|c|c|}
\hline Input: & & Test statistic: & Std. Error: & p-value: \\
\hline a 0.699 & Sobel test: & 7.98245982 & 0.06322337 & 0 \\
\hline b 0.722 & Aroian test: & 7.9679593 & 0.06333843 & 0 \\
\hline$s_{a} 0.053$ & Goodman test: & 7.9970398 & 0.0631081 & 0 \\
\hline$s_{\mathrm{b}} 0.072$ & Reset all & & Calculate & \\
\hline
\end{tabular}

Fig. 8. Soble test depending on the values of estimations and the standard errors of the study variables Reference. This figure was prepared by the researchers based on the outputs of SPSS. V. 24

\begin{tabular}{|c|c|c|c|}
\hline Input: & & Test statist & $p$-value: \\
\hline$t_{a} 13.213$ & Sobel test: & 7.97023107 & 0 \\
\hline$t_{\mathrm{b}} 9.993$ & Aroian test: & 7.95574992 & 0 \\
\hline & Goodman test: & 7.98479159 & 0 \\
\hline & Reset all & \multicolumn{2}{|c|}{ Calculate } \\
\hline
\end{tabular}

Fig. 9. Soble test depending on the values of the T-test.

Reference. This figure was prepared by the researchers based on the outputs of SPSS. V. 24 


\section{Conclusions and recommendations}

\subsection{Conclusions}

Considering the empirical findings of the green organizational strategies and their role on supporting green innovation, the researchers reached several conclusions:

1- The studied company adopted green organizational strategies. Thus, it is considered a real indicator in supporting green innovation.

2- The studied population assured the strong correlation between the green organizational strategies' variable and green innovation variable. The findings showed a strong direct positive correlation between them. This finding shows that whenever the company moved more toward supporting green organizational strategies, that leads to supporting the positive green innovation and that the company gains more knowledge and vision about the extent of these strategies' contribution in enhancing green innovation.

3- The analysis showed the strength of the correlation between the green innovation variable and the sustainable competitive advantage and thus indicates that the production of green products through the company's activities and sectors necessitates the adoption and selection of strategies that consider the best use of the available materials of the company (input) and changing them into products (outputs) that meet the clients and customers' needs and thus contribute to enhancing the sustainable competitive advantage.

4- The statistical analysis findings showed that the green organizational strategies have a direct impact on the sustainable competitive advantage less than the indirect impact on the existence of green innovation. Yet, the green innovation variable has supported the green organizational strategies' impact in enhancing the sustainable competitive advantage in the studied company.

\subsection{Recommendations}

Considering the previous conclusions, the researchers thus present several recommendations that can contribute to enhancing green innovation in the studied company as follows:

1- The company's management should put more dedication to green innovation that supports the company's green status and image through the employees' and workers' awareness in environmental issues and bylaws as well as the company's green orientation toward green products and operations through training programs and internal bulletins and lists.

2- The studied company should increase environmental awareness by emphasizing the use of scientific methods and approaches in getting rid of wastage and guiding material, resources, and energy consumption to achieve environmental sustainability.

3- The studied company's higher management should adopt green organizational strategies that contribute to supporting innovative ideas to increase green innovation to provide products of high quality and thus supporting the company's sustainable competitive advantage.

\section{References}

[1] Amores-Salvadó, J., Martin-de Castro, G., \& Navas-López, J. E.: The importance of the complementarity between environmental management systems and environmental innovation 
capabilities: A firm level approach to environmental and business performance benefits. Technological forecasting and social change, 96, 288-297, (2015).

[2] Zilahy, G.: Organizational factors determining the implementation of cleaner production measures in the corporate sector. Journal of Cleaner production, 12(4), 311-319, (2004)

[3] Bansal, P., \& Roth, K.: Why companies go green: A model of ecological responsiveness. Academy of management journal, 43(4), 717-73, (2000.

[4] Huang, X. X., Hu, Z. P., Liu, C. S., Yu, D. J., \& Yu, L. F.: The relationships between regulatory and customer pressure, green organizational responses, and green innovation performance. Journal of Cleaner Production, 112, 3423-3433, (2016)

[5] Zailani, S., Govindan, K., Iranmanesh, M., Shaharudin, M. R., \& Chong, Y. S.: Green innovation adoption in automotive supply chain: the Malaysian case. Journal of Cleaner Production, 108, 1115$112,(205)$

[6] Colwell, S. R., \& Joshi, A. W.: Corporate ecological responsiveness: Antecedent effects of institutional pressure and top management commitment and their impact on organizational performance. Business Strategy and the Environment, 22(2), 73-91, (2013)

[7] Unnikrishnan, S., \& Hegde, D. S.: Environmental training and cleaner production in Indian industry-A micro-level study. Resources, conservation and recycling, 50(4), 427-441, (2007)

[8] Demirel, P., \& Kesidou, E.: Stimulating different types of eco-innovation in the UK: Government policies and firm motivations. Ecological Economics, 70(8), 1546-1557, (2011)

[9] Clausen, T. H.: External knowledge sourcing from innovation cooperation and the role of absorptive capacity: empirical evidence from Norway and Sweden. Technology Analysis \& Strategic Management, 25(1), 57-70, (2013)

[10] Lin, H., Zeng, S. X., Ma, H. Y., Qi, G. Y., \& Tam, V. W.: Can political capital drive corporate green innovation? Lessons from China. Journal of cleaner production, 64, 63-72 (2014)

[11] Woo, C., Chung, Y., Chun, D., Han, S., \& Lee, D.: Impact of green innovation on labor productivity and its determinants: An analysis of the Korean manufacturing industry. Business Strategy and the Environment, 23(8), 567-576, (2014)

[12] Song, W., \& Yu, H.: Green Innovation Strategy and Green Innovation: The Roles of Green Creativity and Green Organizational Identity. Corporate Social Responsibility and Environmental Management, 25(2), 135-150, (2018)

[13] Ingham. Galia, F., M., \& Pekovic, S.: Incentives for green innovations in French manufacturing firms. International Journal of Technology Management \& Sustainable Development, 14(1), 3-15 (2015)

[14] Abdullah, M., Zailani, S., Iranmanesh, M., \& Jayaraman, K.: Barriers to green innovation initiatives among manufacturers: the Malaysian case. Review of Managerial Science, 10(4), 683-709, (2016)

[15] Chen, Y. S., Lai, S. B., \& Wen, C. T.: The influence of green innovation performance on corporate advantage in Taiwan. Journal of business ethics, 67(4), 331-339, (2006)

[16] Chen, Y. S., \& Chang, K. C.: The nonlinear effect of green innovation on the corporate competitive advantage. Quality \& Quantity, 47(1), 271-286, (2013)

[17] Caracuel. Aguilera, J., \& Mandojana. Ortiz-de, N.: Green innovation and financial performance: An institutional approach. Organization \& Environment, 26(4), 365-385, (2013)

[18] Yang, L. R., Chen, J. H., \& Li, H. H.: Validating a model for assessing the association among green innovation, project success and firm benefit. Quality \& Quantity, 50(2), 885-899, (2016)

[19] Hong. Yang, \& Jian. Zhang, J.: Research on Driving Factors of Green Innovation in China's Auto Parts Manufacturing Enterprises. Advanced Materials Research, Vol. 805, pp. 1685-1691, (2013)

[20] Seman, N. A. A., Zakuan, N., Jusoh, A., Arif, M. S. M., \& Saman, M. Z. M.: The relationship of green supply chain management and green innovation concept. Procedia-Social and Behavioral Sciences, 57, 453-457, (2012)

[21] Chiou, T. Y., Chan, H. K., Lettice, F., \& Chung, S. H.: The influence of greening the suppliers and green innovation on environmental performance and competitive advantage in Taiwan. Transportation Research Part E: Logistics and Transportation Review, 47(6), 822-836, (2011) 
[22] Iranmanesh, M., Zailani, S., Moeinzadeh, S., \& Nikbin, D.: Effect of green innovation on job satisfaction of electronic and electrical manufacturers' employees through job intensity: personal innovativeness as moderator. Review of Managerial Science, 11(2), 299-313, (2015)

[23] Guoyou, Q., Saixing, Z., Chiming, T., Haitao, Y., \& Hailiang, Z.: Stakeholders' influences on corporate green innovation strategy: a case study of manufacturing firms in China. Corporate Social Responsibility and Environmental Management, 20(1), 1-14, (2013)

[24] Chen, P. C., \& Hung, S. W.: Collaborative green innovation in emerging countries: a social capital perspective. International Journal of Operations \& Production Management, 34(3), 347-363, (2014)

[25] Hakkak, M., \& Ghodsi, M.: Development of a sustainable competitive advantage model based on balanced scorecard. International Journal of Asian Social Science, 5(5), 298-308, (2015)

[26] Hoffman, N. P.: An examination of the" sustainable competitive advantage" concept: past, present, and future. Academy of marketing science review, 41-16, (2000) 